\title{
Research on the Influence of TFP on High-Quality Development in China
}

\author{
Xin Sun ${ }^{1}$, Dongnan Sui ${ }^{1}$, Kun Chang ${ }^{2}$, Gang Wang, \\ ${ }^{1}$ Institute of Statistics and Applied Mathematics, Anhui University of Finance \& Economics, Bengbu, 233030, China. \\ ${ }^{2}$ Institute of Languages and Media, Anhui University of Finance \& Economics, Bengbu, 233030, China. \\ ${ }^{3}$ Institute of Economics, Anhui University of Finance \& Economics, Bengbu, 233030, China.
}

\begin{abstract}
How to cite this paper: Xin Sun, Dongnan Sui, Kun Chang, Gang Wang. (2021) Research on the Influence of TFP on High-Quality Development in China. Journal of Applied Mathematics and Computation, 5(3), 154-164.

DOI: 10.26855/jamc.2021.09.002
\end{abstract}

Received: July 2, 2021

Accepted: July 26, 2021

Published: August 11, 2021

*Corresponding author: Gang Wang, Institute of Economics, Anhui University of Finance \& Economics, Bengbu, 233030, China.

Email: actswg@163.com

\begin{abstract}
To promote high-quality economic development is the fundamental requirement for current and future development. Total Factor Productivity (TFP) which represents the degree of high-quality development is popularly researched and studied. Obviously, TFP is an important factor affecting high-quality development, but the system of high-quality development should be more detailed and comprehensive, and the specific relationship between the two is rarely studied in literature. Based on 2009-2017 panel data of China's 30 provinces (municipalities), this article empirically analyzses the impact of TFP on development of high quality. Firstly, from the perspective of the five concepts and of quality improvement, this article establishes the high quality development index evaluation system. It also measures the provincial TFP in our country. Secondly, it studies the impact of TFP on provincial quality and economic development of our country, using Data Development Analysis (DEA), Stata software based panels autoregressive model, and spatial econometric methods. Results show that: First, there is a causal relationship between TFP and high-quality development, and TFP has a positive impact on high-quality economic development. Second, the development of the financial sector also has a positive impact on high-quality development. Based on this, the paper puts forward policy suggestions to effectively promote the high-quality development of China's economy, so as to promote the long-term balanced and sustainable development of China's economy.
\end{abstract}

\section{Keywords}

High-Quality Development, TFP, DEA, PVAR, Panel Space Regression

\section{Introduction}

Since the 19th National Congress of the Communist Party of China, China's economy has shifted from a stage of high-speed development to a stage of high-quality development. Transforming the economic growth pattern to promote high-quality development of the Chinese economy is the focus. China's economic growth mode must change from the traditional "extensive growth" to "intensive growth". To accelerate the shift from a growth model driven by investment scale and factor-driven development to one driven by innovation, we must give top priority to the quality and performance of economic growth, take supply-side structural reform as our main task, promote change in the quality, efficiency and growth drivers of economic development, and raise TFP. Most of the previous studies on economic development focused on the quantitative growth of the economy, but the quantitative growth for the current society is not the foundation of development, for only the improvement of economic quality can promote the steady development of China's economy. The improvement of economic quality means high-quality economic development, which is the requirement of 
China's economic development at present. The improvement of TFP is an important driving force and source to promote high-quality economic development. Therefore, the impact of TFP on high-quality economic development is the focus of attention. Moreover, in quantitative research, many scholars use TFP to measure the degree of high-quality development. Obviously, TFP is an important influencing factor for high-quality development, but the system of high-quality development should be more detailed and comprehensive. How exactly is the quantitative relationship between the two is worth studying.

Taking provinces as the research object, this paper constructs the evaluation index system of high-quality development, measures the degree of high-quality development, and calculates the TFP, and then analyzes whether there is a causal relationship between the two, as well as whether there is spatial spillover effect of the impact of TFP on high-quality development. It also explains whether TFP can be used as an important index to measure quality development.

\section{Literature Review and Hypothesis}

\subsection{Connotation and measurement of high-quality development}

The 19th National Congress of the Communist Party of China (CPC) proposed for the first time that China's economy should be upgraded qualitatively, shifting from high-speed growth to high-quality development. Only by implementing the new vision of innovative, coordinated, green, open and shared development can China achieve high-quality development. Since the concept of high-quality development was put forward by China, it is a unique economic development problem in China. Therefore, the concept of high-quality development has not been clearly put forward by foreign countries. However, foreign scholars' evaluation and research on economic development are relatively insufficient. At present, the literature on the study of high-quality economic development has been relatively rich. Scholars have analyzed the connotation of high-quality economic development from different perspectives. Zhang Junkuo pointed out that the essential connotation of high-quality development is efficient, fair, green and sustainable development starting from the main contradiction of Chinese society [1]. Song Mingshun and Zhang Xia put forward in their research on economic development that the quality of economic development refers to the degree of social satisfaction and the degree of compatibility with sustainable development [2]. Huikang and Chao Xiaojing believed that in a broad sense, it is more reasonable to measure the quality of economic growth with all factors except the quantity of economic growth [3]. High-quality development is measured from all aspects of our country, so it is believed that the connotation of high-quality development is innovation as the driving force, regional coordination, open sharing, high quality and high efficiency of sustainable development, namely the five development concepts and improve quality and efficiency.

For the construction of the indicator system of high quality development, the literature has conducted effective studies from different perspectives. Li Jinchang constructed an evaluation system for high-quality development from two aspects of the main social contradiction: "people's needs for a better life" and "unbalanced and inadequate development" [4]. Zhang Junkuo analyzed and constructed the system from the following aspects: high efficiency of resource allocation, stable economic operation, improvement of industrial and agricultural products and service quality, upgrading of technical level, improvement of people's living quality, balanced distribution in all aspects and sustainable development [1]. Shi Fu measured the indicator system of high-quality economic development from the basic level of growth and the social level in the study of high-quality economic development among provinces in China [5]. Miao Junwei and Feng Hua constructed an indicator system of high-quality development from the perspective of "Three Views", and established indicators from the aspects of factors, industry and society [6]. Foreign studies on high-quality economic development mainly established an index system to measure high-quality development from the perspective of human and nature and sustainable development. Montfort measured high-quality development in terms of "strong, stable and sustainable growth" and other aspects [7]. Martin Fritz and Max Koch analyzed economic development from three aspects: ecological development, social inclusiveness and people's quality of life [8].

\subsection{Connotation and measurement of TFP}

At present, there are many researches on TFP in China. Different scholars have different opinions on the connotation of TFP. It was first used by Solow to calculate the components of the sources of growth in long-term economic growth. Nowadays, most scholars attribute the connotation of TFP to the contributions of other factors that contribute to economic growth when the input variables such as capital, labor and land remain unchanged. Liu Zhichao pointed out that the single analysis of the change of a certain input factor cannot measure the TFP, and the TFP must be measured by comparing all input production factors with the total output [9]. Fu Yong and Bai Long believed that TFP is growth efficiency, that is, output growth promoted by technological progress and economies of scale in addition to capital and labor input [10]. Since TFP contains many production factors but some factors are difficult to be counted, most scholars believe that TFP is the contribution of other factors to economic growth when the input of labor, capital, land and talent education 
remains unchanged on the basis of the definition of TFP.

To measure the TFP, most scholars use Malmquist index, Solow residual method, algebraic exponential method and other methods to measure the TFP. For example, Fu Yong, Li Kaijie and Qu Ruxiao used DEA-Malmquist index to measure the TFP after China's reform and opening up, considering the input indexes of capital and labor and GDP as output indexes [10-11]. Wang Lina used the Malmquist index method to measure the total factor production of China's iron and steel industry [12]. Chao Xiaojing and Ren Baoping used Solow residual method to calculate TFP and contribution degree of TFP to measure the quality of economic growth [13].

\subsection{Analysis of the impact of TFP on high quality development}

Studies on TFP and high-quality development all point out that the improvement of TFP is an important factor to promote high-quality economic development. Some scholars analyze the relationship between the two from a qualitative perspective. Jiang Zhu pointed out that to improve the high-quality development of China's economy, the core problems restricting the improvement of China's TFP must be solved first, and independent innovation has sustainable room for the improvement of TFP in the long run [14]. Liu Zhibiao believed that TFP presented an "inverted U" shape under the influence of structural transformation. When it was to the left of the peak value, structural transformation would improve TFP and thus promote high-quality economic development [15]. Cheng Guangbin and Wang Chaoyang studied the spatial non-linear relationship between TFP and high-quality development, and found that TFP presented an "inverted U-shaped" promoting relationship to high-quality economic development [16]. Sheng Laiyun pointed out that the improvement of TFP is the main reason for promoting China's future rapid economic development [17]. There are also some scholars who analyzed the relationship between them from a quantitative perspective. In the analysis of China's economic growth, Ru Shaofeng found that the decline of China's economic growth rate was mainly caused by the decline of China's TFP which resulted from the change of technical efficiency and scale efficiency, and that the main driving force for high-quality economic development was the improvement of TFP and labor productivity. From two angle measuring high quality industrial and social development and through the establishment of the spatial econometric model studies [18], Xu Peng-jie found that for the high quality development of our country to improve TFP has very important significance, and found that the TFP level to a certain extent is affected by foreign capital, thus indirectly to increase utility generated by the high quality and economic development [19]. Through the above studies on high-quality economic development and TFP, most scholars have analyzed the relationship between them from qualitative and quantitative aspects, but few scholars have studied the spatial effect between them. Therefore, this paper expands as follows: Based on the measurement of high-quality development and TFP, panel autoregression (PVAR) was established from the perspective of spatial distance to analyze the contribution rate of TFP to high-quality economic development, and spatial Dupin model (SDM) was established to analyze whether there is spatial spillover effect between the two. Based on the analysis of the effect of TFP on high-quality economic development, this paper puts forward the following hypotheses:

H1: There is a causal relationship between TFP and high-quality economic development, in which the change of one index will lead to the change of another index, that is, TFP is the cause of high-quality economic development, and high-quality economic development is also the cause of TFP.

H2: TFP has a significant positive impact on high-quality economic development, that is, the higher the TFP is, the higher the high-quality development degree is.

H3: TFP has positive spillover effect on high-quality economic development.

\section{High-quality Development and TFP Measurement}

Taking provincial data as samples, this paper measures the high quality development degree of each province and calculates the TFP of each province.

\subsection{Measurement of high quality development}

\subsubsection{Methods select}

At present, most scholars use analytic hierarchy process (AHP), factor analysis (FA) and principal component analysis (PCA) to evaluate high quality development. Equivalence weighting method is used here to give weight to each index, and linear weighted sum method is used to calculate the comprehensive evaluation value of high-quality development. The calculation formula is as follows:

$$
X_{i}^{t}=\sum_{j=1}^{n} \lambda_{j} X_{i j}^{t}, \sum_{j=1}^{n} \lambda_{j}=1
$$

where $X_{i j}^{t}$ is the data after dimensionality elimination after preprocessing of the original data. The dimensionality eli- 
mination formula is as follows:

$$
X=\left(X_{i j}\right)_{n \times m}, X_{i j}= \begin{cases}\left(a_{i j}-\min _{j} a_{i j}\right) /\left(\max _{j} a_{i j}-\min _{j} a_{i j}\right) & a_{i j} \in I_{1} \\ \left(\max _{j} a_{i j}-a_{i j}\right) /\left(\max _{j} a_{i j}-\min _{j} a_{i j}\right) & a_{i j} \in I_{2}\end{cases}
$$

\subsubsection{Establishment of index system}

High-quality development is the internal requirement of China's economic development in the future. First of all, we must implement the new concept of development in order to enhance China's high-quality development. Secondly, high-quality economic development is not only about scale development but also about quality. Improving quality and efficiency is an inherent goal, so it is necessary to use indicators of improving quality and efficiency to reflect the degree of high-quality development. Therefore, this paper selects 18 second-level indicators from the six first-level indicators of five development concepts, namely innovation, coordination, green, openness, sharing and improvement of quality and efficiency, to jointly construct the evaluation index system of high-quality development. Referred to relevant literature and studied, the evaluation index system of high-quality development was established according to the criteria of rationality, scientificity and availability. See Table 1 for details.

Table 1. Provincial high quality development evaluation index system

\begin{tabular}{|c|c|c|c|}
\hline $\begin{array}{l}\text { First level indica- } \\
\text { tor }\end{array}$ & $\begin{array}{l}\text { Second level } \\
\text { indicator }\end{array}$ & Second level indicator & $\begin{array}{l}\text { Index proper- } \\
\text { ties }\end{array}$ \\
\hline \multirow{18}{*}{$\begin{array}{l}\text { High-quality de- } \\
\text { velopment }\end{array}$} & \multirow{3}{*}{ degree of opening } & $\begin{array}{l}\text { Openness of foreign capital = actual utilization of foreign capi- } \\
\qquad \text { tal/GDP }\end{array}$ & $\begin{array}{l}\text { Positive indi- } \\
\text { cator }\end{array}$ \\
\hline & & Foreign trade openness = total import and export/ GDP & $\begin{array}{l}\text { Positive indi- } \\
\text { cator }\end{array}$ \\
\hline & & $\begin{array}{c}\text { Ratio of overseas tourists }=\text { number of inbound tourists/total number } \\
\text { of tourists }\end{array}$ & $\begin{array}{l}\text { Positive indi- } \\
\text { cator }\end{array}$ \\
\hline & \multirow{3}{*}{$\begin{array}{l}\text { degree of innova- } \\
\text { tion }\end{array}$} & $\begin{array}{c}\text { Inintensity of local fiscal investment in science and technology = } \\
\text { R\&D expenditure of industrial enterprises above designated } \\
\text { size/GDP }\end{array}$ & $\begin{array}{l}\text { Positive indi- } \\
\text { cator }\end{array}$ \\
\hline & & $\begin{array}{c}\text { Number of patents per capita = total number of patents autho- } \\
\text { rized/total number of people }\end{array}$ & $\begin{array}{l}\text { Positive indi- } \\
\text { cator }\end{array}$ \\
\hline & & $\begin{array}{c}\begin{array}{c}\text { Technology market share }=\text { technology market turnover/gross re- } \\
\text { gional product }\end{array}\end{array}$ & $\begin{array}{l}\text { Positive indi- } \\
\text { cator }\end{array}$ \\
\hline & \multirow{3}{*}{$\begin{array}{l}\text { degree of coordi- } \\
\text { nation }\end{array}$} & Regional income sharing level = per capita GDP/per capita GDP & $\begin{array}{l}\text { Positive indi- } \\
\text { cator }\end{array}$ \\
\hline & & $\begin{array}{c}\text { Regional consumption sharing level = resident consumption lev- } \\
\text { el/national resident consumption level }\end{array}$ & $\begin{array}{l}\text { Positive indi- } \\
\text { cator }\end{array}$ \\
\hline & & Proportion of added value of the tertiary industry & $\begin{array}{l}\text { Positive indi- } \\
\text { cator }\end{array}$ \\
\hline & \multirow{3}{*}{ degree of green } & Proportion of nature reserves in the area under jurisdiction & $\begin{array}{l}\text { Positive indi- } \\
\text { cator }\end{array}$ \\
\hline & & $\begin{array}{c}\text { Waste water discharge per unit GDP = total waste water discharge } \\
\text { per region/gross regional product }\end{array}$ & $\begin{array}{l}\text { Negative indi- } \\
\text { cator }\end{array}$ \\
\hline & & $\begin{array}{l}\text { Emissions per unit of GDP = regional sulfur dioxide emis- } \\
\text { sions/regional gross domestic product }\end{array}$ & $\begin{array}{l}\text { Negative indi- } \\
\text { cator }\end{array}$ \\
\hline & \multirow{3}{*}{ degree of sharing } & Number of health technicians per 10,000 people & $\begin{array}{l}\text { Positive indi- } \\
\text { cator }\end{array}$ \\
\hline & & Normal high school teachers than & $\begin{array}{l}\text { Positive indi- } \\
\text { cator }\end{array}$ \\
\hline & & Urban unemployment rate & $\begin{array}{l}\text { Negative indi- } \\
\text { cator }\end{array}$ \\
\hline & \multirow{3}{*}{$\begin{array}{l}\text { improve quality } \\
\text { and efficiency }\end{array}$} & Labor productivity of the whole society = GNP/national employment & $\begin{array}{l}\text { Positive indi- } \\
\text { cator }\end{array}$ \\
\hline & & Tax revenue as a share of GDP & $\begin{array}{l}\text { Positive indi- } \\
\text { cator }\end{array}$ \\
\hline & & The ratio of GDP to fixed asset investment & $\begin{array}{l}\text { Positive indi- } \\
\text { cator }\end{array}$ \\
\hline
\end{tabular}




\subsubsection{Source of data}

The actual utilization of foreign capital, total import and export volume, number of inbound tourists and total number of tourists are from the Statistical Yearbook of each province, and the other data are from the Statistical Yearbook of China.

\subsection{TFP measurement}

Data envelopment analysis (DEA) has no requirement on the production function form of input and output and does not need to make behavioral assumptions, which reduces the constraint conditions for calculation. Therefore, this paper adopts DEA to calculate the TFP of each province.

\subsubsection{Index selection}

Output index: GDP of each province (100 million yuan) was selected for measurement. The GDP data of each province were all from China Statistical Yearbook.

Labor input index: the unified use of the number of registered employment to represent the data from the "China Statistical Yearbook".

Capital input amount: the capital stock of each province is estimated according to the most widely used perpetual inventory method (100 million yuan). The capital input amount calculated by different selection of fixed assets depreciation rate is different, and the selection of initial capital stock also has an impact on the capital stock. Based on the capital stock in 2000, the growth rate method is used to calculate the initial capital stock:

$$
K_{0}=I_{0}(1+g) /(g+\delta)
$$

$\mathrm{K}_{0}$ is the initial capital stock, $\mathrm{I}_{0}$ is the total capital formation, $\mathrm{g}$ is the growth rate of investment, and $\delta$ is the depreciation rate of fixed assets. The total amount of capital formation is measured by the total amount of fixed capital formation of each province. The depreciation rate of fixed assets is calculated by referring to relevant literature and combining relevant literature results. 9.6\% is used here. The capital stock after 2000 is calculated using the perpetual inventory method.

$$
K_{i}=\frac{I_{i}}{p_{i}}+(1-\delta) K_{i-1}
$$

where, $p_{i}$ is the capital price index, where the fixed asset investment price index is used instead.

Education input: the input of talents plays a positive role in promoting the economic development of a region, and the input degree of talents training varies from region to region. Education investment (100 million yuan) is selected to represent the input of each region to talent training. Education investment is an important support condition for talent training, and the data are from China Statistical Yearbook.

Land input: The built-up area (square kilometers) of each province is selected to measure the land input of each region, with data from China Statistical Yearbook.

\section{Empirical analysis}

The quantitative relationship between high quality development and TFP needs to be analyzed by constructing an econometric model. Before the establishment of the panel regression model, it is necessary to ensure that the correlation between variables is not a pseudo-regression caused by the common development trend, so it is necessary to conduct unit root test on the data first to determine whether it is stable data.

\subsection{Variable selection}

\subsubsection{Explained variable}

This paper takes high-quality development as the explained variable and measures it from six dimensions of innovation, coordination, green, openness, sharing and quality and benefit based on the data of 30 provinces and municipalities from 2013 to 2017.

\subsubsection{Exposition variable}

In the study of industrial structure upgrading, Liu Zhibiao and An Tongliang (2002) used Moore structure change value index to calculate that industrial structure adjustment had a promoting effect on economic growth when studying the impact of industrial structure adjustment on China's economic growth. Yuan Fuhua (2012) found in the analysis of economic growth factors in developed countries that economic growth slowed down after 1970 due to the service-oriented industrial structure. Because China is a big agricultural country, the level of agricultural modernization can be a good measure of the structural upgrading of agriculture. At present, China's economy becomes more digital. The arrival of the era of big data promotes the development of the Internet and makes the development of all industries inseparable from 
the network platform. The intelligent economy has been the general trend, so the level of information modernization is introduced here to measure the structural upgrading of various industries. Industrial agglomeration in space can save the cost of material flow and improve production efficiency. Since the proportion of tertiary industry in the national economy in China is lower than that of manufacturing industry, the industrial agglomeration degree of manufacturing industry is selected to represent the industrial agglomeration degree of China. In summary, the upgrading of industrial structure is measured from three perspectives: the level of agricultural modernization, the level of information modernization and the degree of industrial agglomeration. As a big agricultural country, the development of agriculture is an indispensable part of high-quality economic development. This paper measures the level of agricultural modernization in China by comparing the total power of agricultural machinery with the planting area of crops in each province. Information modernization is inseparable from the development of the Internet. Here, the level of information modernization in each province is measured by the Internet penetration rate. The industrial agglomeration degree of China is measured by the ratio of the proportion of the manufacturing urban employed persons in each region to the proportion of the national manufacturing urban employed persons in the whole country. Entropy method is used to calculate the upgrading of industrial structure in each province.

"Financial life, economic life; Financial stability, economic stability". It can be seen that the development of financial industry and China's economic development are interdependent. Through the analysis of the development of financial industry, we can see that the development of China's financial industry has a certain impact on the high quality of economic development. Therefore, the development of financial industry is introduced as the explanatory variable and the proportion of the added value of financial industry in the GDP of each province and region is used to measure the development degree of China's financial industry.

Based on the above analysis of the factors influencing high-quality economic development, combined with the rationality and accessibility of the indicators, TFP, industrial structure upgrading and financial industry development are finally selected as explanatory variables for quantitative analysis.

\subsection{Empirical analysis}

\subsubsection{Unit root test}

Since the data type used in this paper is short panel data, and the data time in this paper is fixed, the variable samples of each province fixed, it is more suitable for IPS test to test whether the data exists unit root. The logarithms of high-quality economic development and financial development are used to mitigate the trend of the data. The unit root test results of high-quality development logarithm (lnhq), TFP (tfp), industrial structure upgrading (upg) and financial industry development (lne) are obtained by STATA command. The statistical value of high quality development (lnhq) is -3.1701 and its $p$ value is 0.0008 less than $\alpha=0.01$. Therefore, it can be considered that the hypothesis of panel unit root is rejected when the probability of making errors is less than $1 \%$, and that the high quality development tends to be stable. The statistical value of TFP (tfp) is -1.4057 and its $p$ value is 0.0799 , which is less than $\alpha=0.01$. Therefore, it can be considered that the hypothesis of panel unit root is rejected when the probability of error is less than $10 \%$, and the TFP of each province is considered as stationary data. The statistic of industrial structure upgrading (upg) is -1.5879 and its $\mathrm{p}$ value is 0.0562 , which is less than $\alpha=0.01$. Therefore, the hypothesis of panel unit root can be rejected and the industrial structure upgrading is considered as stationary data. The statistic of financial industry development (lne) is -2.2733. Therefore, it can be considered that the assumption of panel unit root is rejected under the condition that the probability of error is less than $5 \%$, and the financial industry development can be considered as stable data.

\subsubsection{Panel autoregression (PVAR)}

In order to analyze the relationship between TFP and high-quality development, panel autoregressive analysis of the impact between TFP and high-quality development was first conducted.

(1) Determine the optimal lag order: According to the minimum information content criterion, combining the values of MBIC, MAIC and MQIC, we can know that the first order of delay should be selected as the optimal lag order. Therefore, the lagging first-order value was selected to perform panel autoregression and test the stability of the model. The test results are as follows:

Table 2. Eigenvalue

Eigenvalue

\begin{tabular}{ccc} 
Intrinsic value & Virtual value & Coefficient \\
\hline 0.9456296 & 0 & 0.9456296 \\
0.7873604 & 0 & 0.7873604 \\
\hline
\end{tabular}


As shown in Table 2, all the eigenvalues are less than 1, that is, thePvar system is stable, and the eigenvalues are close to 1 , indicating a strong continuity of impact.

(2) Granger causality test: The Granger causality test is used to determine whether TFP has a certain "predictive ability" to high-quality development. The Granger test can be performed for stationary sequences and unit root processes with co-integration relations. According to the above results, Granger test can be carried out to test the causality of each variable. The test results are as follows:

Table 3. Granger causality test

\begin{tabular}{lccc}
\hline & & Statistic & p value \\
\hline Lnq & tfp & & 0.002 \\
& all & 0.9248 & 0.002 \\
tfp & & 0.9248 & \\
& lnq & & 0.314 \\
& all & 1.015 & 0.314 \\
\hline
\end{tabular}

As can be seen from the above table, since the null hypothesis TFP is not the cause of high-quality development and its $p$ value of 0.002 is less than $\alpha=0.01$, the null hypothesis is rejected and TFP is considered to be the cause of high-quality development. Secondly, the null hypothesis is that high-quality development is not the cause of TFP, and its $p$ value is 0.315 , which is greater than $\alpha=0.1$. Therefore, the null hypothesis is accepted that high-quality development is not the cause of TFP.

(3) Pulse response analysis: TFP is the reason for high quality development. One unit of TFP change is analyzed to see how much impact it has on high-quality development. It is also necessary to analyze how much impact a one-unit change in TFP has on high-quality development. Therefore, through the orthogonalized impulse response function, we can observe the impact of the change of TFP on high-quality development. The results are as follows:

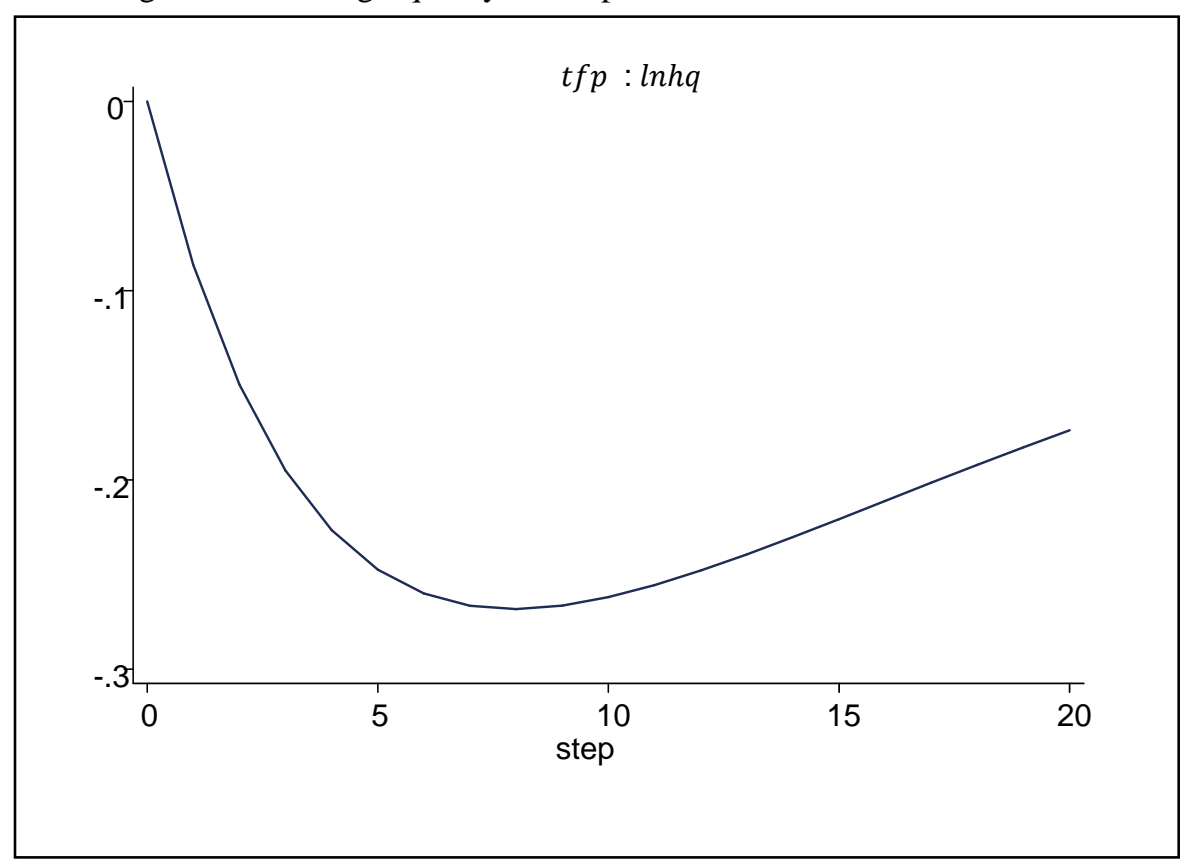

Figure 1. Impulse response diagram.

It can be seen from Figure 1 that the decrease of TFP will reduce the level of high-quality development, that is, the decrease of TFP will cause all regions to maintain a relatively low rate of high-quality development in the next few years to stimulate the economy.

(4) Variance decomposition: In order to further understand the contribution of TFP to quality development, a dynamic 
analysis was performed using variance decomposition. The results are as follows:

Table 4. Variance decomposition

\begin{tabular}{ccc}
\hline Response variable $\operatorname{lnh} q$ & $\ln q$ & $t f p$ \\
\hline 1 & 1 & 0 \\
2 & 0.7945 & 0.2055 \\
3 & 0.5791 & 0.4209 \\
4 & 0.4339 & 0.5661 \\
5 & 0.3417 & 0.6583 \\
6 & 0.2815 & 0.7185 \\
7 & 0.2405 & 0.7595 \\
8 & 0.2116 & 0.7884 \\
9 & 0.1904 & 0.8096 \\
10 & 0.1745 & 0.8255
\end{tabular}

As shown in Table 4, the prediction variance of lnhq from itself gradually decreased from the second stage, while the prediction variance from TFP gradually increased. By the 10th stage of the prediction, it could be seen that the prediction variance from $\mathrm{lnhq}$ itself was $17.45 \%$, while the prediction variance from TFP was $82.55 \%$. This indicates that high quality development is greatly affected by TFP, and TFP is indispensable for high quality development. From the above analysis, we can see that there is indeed a causal relationship between TFP and high-quality development, but TFP is the cause of high-quality development, while high-quality development is not the cause of TFP. So let's assume that the first half of $\mathrm{H} 1$ is true.

\subsubsection{Model setting and result analysis}

Through the above analysis, it can be seen that the data are stationary data, so there will be no pseudo-regression phenomenon caused by trend, which means that regression analysis can be conducted on the data.

Panel space econometric model: Since there may be certain mutual influences between different regions for high-quality economic development, a panel space model is constructed to verify the relationship between TFP and high-quality development. The reciprocal matrix of geographical distance is used to perform the regression and test of panel space. Before building the model, the spatial effect of the data was first tested. First, the high-quality development data was converted into cross-section data for global Moran test. The results are shown in the table below:

Table 5. High quality development Moran's I test

\begin{tabular}{ccccc}
\hline year & 2009 & 2012 & 2015 & 2016 \\
\hline Moran index & 0.060 & $0.089 *(1.303)$ & $0.201^{* * *}$ & $0.102^{*}$ \\
& $(0.998)$ & & $(2.438)$ & $(1.417)$
\end{tabular}

Notes: Statistics are in parentheses. * indicates significant at $10 \%$ significance level, ** at $5 \%$ significance level, and *** at $1 \%$ significance level.

According to the results of Moran index in some years, it can be seen that high-quality development has inter-regional correlation and positive correlation, showing that provinces with high high-quality development degree adjacent to each other have higher high-quality development, while provinces with low high-quality development degree adjacent to each other have lower high-quality development. This indicates that high-quality development is unbalanced among provinces in China. Some regions with low level of high-quality economic development may learn from neighboring provinces and cities with better economic development for development, and thus there is a positive correlation between the high- quality development degree of neighboring regions. On the whole, Moran index I shows an upward trend, indicating that high-quality development between provinces in China is influenced by neighboring regions.

The spatial effect test is carried out to determine whether the data is suitable for panel space measurement. Moran from the test result, spatial error index inspection and Lagrange multiplier, and the steady Lagrange test $\mathrm{p}$ value is less than 0.01 , spatial lag inspection $\mathrm{p}$ values were less than 0.01 , then there can also be refused to there is no spatial autocorrelation of the null hypothesis, can think of the introduction of the development of the financial sector data there is also a space effect. Therefore, a spatial econometric model can be constructed for verification. 
The following is the establishment of Spatial Durbin Model (SDM). The 0-1 matrix and reciprocal matrix of geographical distance are used as the spatial weight matrix to establish models. The results are as follows:

Table 6. Spatial Dupin Model Results

\begin{tabular}{ccc}
\hline Variable & M1 $(0-1$ matrix $)$ & M2(Geographical distance reciprocal matrix) \\
\hline tfp & $0.3452^{* * *}(0.1320)$ & $0.3482^{* * *}(0.1324)$ \\
upg & $0.0205(0.0724)$ & $-0.0010(0.0755)$ \\
lne & $0.1678^{* *}(0.0769)$ & $0.1430^{*}(0.0781)$ \\
Wx & & \\
upg & $1.1694^{* * *}(0.3684)$ & $0.4190^{*}(0.2440)$ \\
lne & $-0.4633^{* * *}(0.1886)$ & $-0.4215^{* * *}(0.1617)$ \\
rho & $0.2951(0.3059)$ & $-0.1202(0.1106)$ \\
sigma2_e & $-0.2420^{* *}(0.0993)$ & $-0.1980^{* *}(0.0862)$ \\
Direct effect & $0.0198^{* * *}(0.0017)$ & $0.0205^{* * *}(0.0018)$ \\
$t f p$ & & \\
upg & $0.3073^{* * *}(0.1381)$ & $0.3373^{* *}(0.1371)$ \\
lne & $0.0360(0.0669)$ & $0.0147(0.0700)$ \\
Indirect effect & $0.1642^{* *}(0.0730)$ & $0.1570^{* *}(0.0746)$ \\
$t f p$ & & \\
upg & $0.9108^{* * * *}(0.2949)$ & $0.3039(0.2006)$ \\
lne & $-0.3977^{* *}(0.1559)$ & $-0.3701^{* * *}(0.1376)$ \\
Total effect & $0.2296(0.2515)$ & $-0.1260(0.0952)$ \\
$t f p$ & $1.2180^{* * * *}(0.3110)$ & $0.6413^{* * * *}(0.2351)$ \\
upg & $-0.3617^{* *}(0.1843)$ & $-0.355^{* *}(0.1722)$ \\
lne & $0.3937(0.2663)$ & $0.0310(0.1242)$ \\
\hline
\end{tabular}

Notes: Standard deviation is in parentheses. * means significant at $10 \%$ significance level, ** at $5 \%$ significance level, and *** at $1 \%$ significance level.

As can be seen from the spatial Durbin model, when the significance level $\alpha=0.05$, the spatial coefficient of Model 1 passes the significance test, suggesting that there is a significant spatial correlation between high-quality economic development, that is, the establishment of the spatial Durbin model is appropriate. From the estimation coefficient of each variable, the results of model M1 and M2 are similar. Among them, the coefficient of TFP is significantly positive when the significance level $\alpha=0.01$, and the coefficient of financial industry development is significantly positive when the significance level $\alpha=0.05$. TFP and financial industry development can promote high-quality economic development. In Model 1 and Model 2, the spatial spillover effect of TFP is positive, that is, it promotes the economic growth of neighboring regions. The spatial spillover effect of industrial structure upgrading is negative, that is, it inhibits the economic growth of adjacent areas. Model 1 and model 2 can be seen that for the upgrading of the industrial structure, there is no significant influence on the development of the high quality, may be because of China's industrial transformation to previous technology and system innovation to have certain dependence, and the implementation of some of the industry policy of industrial upgrading energy underpowered and influence on the development of the cause for the upgrading of the industrial structure of high quality was not significant.

It can be seen from the spatial effect decomposition results that the improvement of TFP in Model 1 and Model 2 can not only promote the high-quality economic development of the local region, but also promote the high-quality economic development of neighboring regions. The upgrading of industrial structure inhibits the economic growth of adjacent areas and has no significant effect on the local economic development. The development of the financial industry can promote the economic development of the region, but the effect of the adjacent areas is not significant. 
According to the analysis, the improvement of TFP means that the improvement of production technology and factor allocation efficiency is conducive to the sustainable development of regional economy and regional economic development in China. Therefore, TFP is indispensable for high-quality development.

\section{Conclusion and Suggestion}

\subsection{Conclusion}

Based on the five development concepts and the improvement of quality and efficiency, this paper selects 18 three-level indicators to construct an index evaluation system, evaluates the high quality development level of 30 provinces in China from 2009 to 2017, determines the indicators to measure the TFP, and uses DEA to calculate the TFP of each province. By constructing the panel autoregressive model and the panel space econometric model, the impact of the change of TFP on the high-quality development of China's economy is empirically analyzed. The results show that:

(1) Through Granger causality test, it is found that TFP is the Granger cause of high-quality development, while high-quality development is not the cause of TFP. Therefore, it is correct to assume that TFP in H1 is of high quality and that there is a causal relationship.

(2) From the perspective of time, the improvement of TFP plays a positive role in promoting high-quality development of China. The improvement of TFP can promote high-quality development of China's economy, and TFP has a significant impact on high-quality development and makes a great contribution, which verifies that hypothesis $\mathrm{H} 2$ is correct. Therefore, it is reasonable for many scholars to use TFP to measure high-quality economic development. Secondly, it can be seen from the results of the model that the development of the financial industry also has a positive impact on high-quality economic development, that is, the development and improvement of the financial industry will promote high-quality economic development.

(3) From the spatial perspective, the TFP of the neighboring regions has a significant promoting effect on the high-quality development of the region, that is, the spatial spillover effect is positive, the industrial structure upgrading of the neighboring regions has a inhibiting effect on the high-quality economic development of the region, the spatial spillover effect is negative, the spillover effect of the financial industry development is not significant.

\subsection{Suggestion}

Policy recommendations are put forward based on the above empirical results:

(1) Raising TFP is all about promoting high-quality economic development in our country. It can be seen from the regression results that the improvement of TFP can promote the high-quality development of China's economy. Under the background that the traditional mode of production cannot adapt to the pace of modern economic development and the marginal output efficiency of factor input decreases, in the future the ascension of TFP would be the main drivers of economic development in China, and the promotion of TFP relies mainly on the technology progress, thus increasing investment in scientific research funds and strengthening of the introduction of technology, strengthening the cultivation of scientific research personnel for subsequent talent supply to provide security, promoting technology progress in China, and enhancing factor allocation efficiency to promote the improvement of TFP.

(2) Actively promoting the development of the financial industry to promote high-quality economic development. Compared with western countries, the development of financial industry in China is relatively late. At present, the development of financial industry still faces some problems. In the context of economic globalization, the financial industry is increasingly affected by the international situation. China's financial industry should be open to the world and promote the structural reform of the financial industry to improve the high-quality development of the economy. Local governments should actively and prudently deal with financial risks and take market and administrative measures to prevent and defuse them. At the same time, we should prevent the excessive development of the financial industry from causing the bubble economy.

(3) Making full use of spatial spillover effect among provinces and cities. To break industry barriers and actively learn advanced technologies in neighboring areas, we should optimize the use of production factors and improve the use efficiency of each factor, and learn from the development experience of rapidly developing areas to improve high-quality economic development.

\section{Acknowledgments}

This study was funded by Humanities and Social Sciences Research Major Project of Education Department of Anhui (SK2020A0017), Natural Science Research Key Project of Universities in Anhui Province (KJ2019ZD45). 


\section{References}

[1] J. K. Zhang. (2019). The Goals and Strategy Path of High-quality Development. Management World, 35, 1-7.

[2] M. S. Song, X. Zhang, and R. H. Yi. (2015). A Study on the Evaluation of the Quality of Economic Development and its Application. Economist, 2, 35-43.

[3] K. Hui and X. J. Chao. (2010). Research on the Quality of Economic Growth: A Literature Review. Seeker, 2, 5-8.

[4] J. C. Li, L. M. Shi, and A. T. Xu. (2019). Probe into the Assessment Indicator on High-quality Development, Statistical Research, 36, 4-14.

[5] B. Shi and B. P. Ren. (2018). A Measurement of China's Provincial Economic High-quality Development, On Economic Problem, 4, 1-6.

[6] J. W. Miao and H. Feng. (2020). Construction and Measurement of Regional High-quality Development Evaluation System, On Economic Problem, 1, 111-118.

[7] Mlachila, Montfort, René Tapsoba, and Sampawende J. A. Tapsoba. (2017). A quality of growth index for developing countries: a proposal. Social Indicators Research, 134, 675-710.

[8] Fritz, et al. (2016). Economic development and prosperity patterns around the world: Structural challenges for a global steady-state economy, Global Environmental Change: Human and Policy Dimensions, 38, 41-48.

[9] Z. C. Zhang. (2019). On the High-quality Development of Chinese Economy from the Perspective of TFP. Economic Research Guide, 32, 5-7.

[10] Y. Fu and L. Bai. (2009). TFP Growth and ITS Determinants in China during the Reform Period (1978-2006): A Malmquist Index Analysis Based on Provincial Panel Data. Journal of Financial Research, 7, 38-51.

[11] K. J. Li and R. X. Qu. (2012). The Effect of Technological Change on China's Carbon Dioxide Emission: An Empirical Analysis Based on the Vector Error Correction Model, China Soft Science, 6, 51-58.

[12] L. N. Wang, X. Tong, and X. M. Sun. (2016). Measurement Analysis of TFP of China's Iron and Steel Industry based on DEA-Malmquist Index Method. Journal of Northwestern Polytechnical University (Social Sciences), 36, 65-70.

[13] X. J. Chao and B. P. Ren. (2008). Economic Transition and Quality of Economic Growth in China: Accounting for Contribution Ratio of TFP, Modern Economic Science, 4, 65-70.

[14] Z. Jiang, T. Ma, and Y. Wang. (2019). Research on the Factors of China's TFP under the Background of High-quality Development. Journal of Guizhou University of Finance and Economics, 1, 37-46.

[15] Z. B. Liu and Y. H. Ling. (2020). Structural Transformation, TFP and High-quality Development. Management World, 36, 88-96.

[16] H. J. Sun and S. G. Wang. (2020). Research on the Disparity of Income, FP and Convergence Hypothesis in China High-Tech Zones. Journal of Industrial Technological Economics, 39, 88-96.

[17] G. B. Cheng and Z. Y. Wang. (2020). Spatial Nonlinear Test of TFP and High-quality Development of Regional Economy. Statistics \& Decision, 36, 23-28.

[18] L. Y. Sheng, T. Li, S. Y. Mao, and L. H. Fu. (2018). Total Factor Productivity Measurement and Forecast of Economic Growth in China. Journal of Statistics and Information, 33, pp. 3-11.

[19] S. F. Ru and B. Y. Wei. (2018). Productivity Explanation and Short-term Prediction of the Change of Potential Economic Growth Rate of China's High-quality Development in the New Era. Journal of Northwest University (Philosophy and Social Sciences Edition), 48, 17-26.

[20] P. J. Xu and P. Yang. (2019). Opening-up, Total Factor Productivity and High-quality Development. Reform of Economic System, 1, 32-38.

[21] Z. B. Liu and T. L. An. (2002). Evolution of Industrial Structure and Economic Growth in China. Nanjing Journal of Social Sciences, 1, 1-4.

[22] F. H. Yuan. (2012). Structural Accelerating and Structural Decelerating in the Long Run Growth: An Exposition. Economic Research Journal, 2, 127-140. 